\title{
Pregnancy induced hypertension (PIH): Beyond pregnancy
}

\section{Osama Osman*}

Department of Medicine, Division of Nephrology, Lehigh Valley Health Network, USA

\section{Short communication}

Contrary to the belief that pregnancy-induced hypertension $(\mathrm{PIH}$, or hypertensive disorders of pregnancy, HDP) and preeclampsia are benign conditions that do not extend harm past pregnancy, the evidence is growing that preeclampsia is a risk factor for future cardiovascular disease. Although most published data indicate that proteinuria during pregnancy does no long-term harm to the mother [1,2], more recent reports indicate that preeclampsia increases the risk of cardiovascular disease [3-7]. Recent research published on November 11, 2019 in the Journal of the American College of Cardiology [7] confirms that women who have gestational hypertension or preeclampsia in at least one pregnancy have a higher cardiovascular risk than women without this history. The authors conclude that a history of HDP can be a useful tool to refine atherosclerotic cardiovascular disease risk assessments. They added "However, future risk of diverse cardiovascular conditions in asymptomatic middle-aged women with prior HDP remains unknown". They also argued that "hypertensive disorders of pregnancy are associated with accelerated cardiovascular aging and more diverse cardiovascular conditions than previously appreciated" and commented that the cardiovascular risk after HDP is largely but not solely mediated by the development of chronic hypertension. Many authorities now regard pregnancy as a "cardiovascular stress test" [8].

There are also reports that preeclampsia increases the risk of end-stage kidney disease later in life $[9,10]$. Thus, in addition to be a "cardiovascular stress test", pregnancy can also be regarded as a "renal stress test". Urinary protein excretion increases in normal pregnancy from $<150 \mathrm{mg} /$ day in non-pregnant individuals to up to $300 \mathrm{mg} /$ day in pregnancy. Thus, the threshold of abnormal protein excretion for the diagnosis of preeclampsia is $>300 \mathrm{mg} / 24$ hours or more than $2+$ by dipstick testing according to the American College of Obstetrics and Gynaecology Guidelines [11,12].

A recent study published by Kristensen et al. in April 2019 [13] reached the same conclusion. They investigated associations between pre-eclampsia and later risk of kidney disease using a nationwide register-based cohort in Denmark [13]. All women with at least one pregnancy lasting at least 20 weeks between 1978 and 2015 were included. Their main outcome measure was the hazard ratios comparing rates of kidney disease between women with and without a history of pre-eclampsia, stratified by gestational age at delivery and estimated the hazard ratio using Cox regression. They concluded that "Pre-eclampsia, particularly early preterm pre-eclampsia, was strongly associated with several chronic renal disorders later in life." They commented that "More research is needed to determine which women are most likely to develop kidney disease after pre-eclampsia, what mechanisms underlie the association, and what clinical follow-up and interventions (and in what timeframe post-pregnancy) would be most appropriate and effective" [13].
Current ACOG criteria for the diagnosis of preeclampsia include increased blood pressure $(\geq 140 / 90 \mathrm{~mm} \mathrm{Hg})$ on at least 2 occasions 4 hours apart, after 20 weeks of gestation, and either proteinuria $(\geq$ $300 \mathrm{mg}$ on a 24 -hour urine collection, UPCR $\geq 0.3 \mathrm{mg} / \mathrm{mg}$, or urine protein dipstick reading $>2+$ if quantitative testing is not available) or, in the absence of proteinuria, high blood pressure plus another severe feature such as renal impairment, low platelets, impaired liver function, pulmonary oedema, or cerebral or visual symptoms $[11,14]$. As we previously reported [15], blood pressure tends to dip in the first trimester of pregnancy. Because current guidelines define preeclampsia as blood pressure $>140 / 90 \mathrm{mmHg}$, increases from its nadir to this value may represent an unrecognized prodrome. Further work is needed to define the normal blood pressure for the pregnant women.

Because the definition of hypertension in pregnancy ( $>140 / 90$ $\mathrm{mmHg}$ ) is not evidence-based, and because blood pressure normally falls by up to $10-15 \mathrm{mmHg}$ early in pregnancy [15], the threshold for the definition of hypertension in pregnancy should probably be lower than the threshold in non-pregnant individuals. Defining hypertension as $>140 / 90 \mathrm{mmHg}$ does not facilitate the early detection of HDP, and the current ACOG criteria for the diagnosis of preeclampsia $[11,14]$ impede early detection of the condition. Early diagnosis of preeclampsia is critical since occurrence early in pregnancy is associated with a worse prognosis. Currently, the only recommended screening tool is blood pressure measurement throughout pregnancy, which does not detect early preeclampsia; more screening tools are needed. Also, current management of preeclampsia remains supportive targeting the prevention of complications by lowering blood pressure and preventing seizures by using antihypertensive medications and/ or magnesium sulfate. Delivery remains the only definitive treatment for pre-eclampsia, and low dose aspirin remains the recommended approach for the prevention of pre-eclampsia in women at high risk.

From the work published by Maynard et al. [16], we learned that placental ischemia is an early event, leading to placental production of a soluble factor(s) that cause maternal endothelial dysfunction resulting in the hypertension, proteinuria, and oedema. The authors confirmed that placental soluble FMS-like tyrosine kinase 1 (sFlt1), an antagonist of VEGF and placental growth factor (PlGF), is upregulated in preeclampsia, leading to increased systemic levels of sFlt1 that decrease after delivery. They also demonstrated that increased circulating sFlt1 in patients with preeclampsia is associated with decreased circulating levels of free VEGF and PlGF, resulting in endothelial dysfunction in

${ }^{\star}$ Correspondence to: Osama Osman, Department of Medicine, Division of Nephrology, Lehigh Valley Health Network, USA, Tel: +1484 5157437; E-mail: osama.osman@lvhn.org

Received: November 13, 2019; Accepted: November 28, 2019; Published: December 03, 2019 
vitro that can be rescued by exogenous VEGF and PlGF. They further reported that the administration of sFlt1 to pregnant rats induces hypertension, proteinuria, and glomerular endotheliosis, the classic lesion of preeclampsia. They concluded that excess circulating sFlt1 contributes to the pathogenesis of preeclampsia. Today, 16 years after their report, we are still seeking novel treatment(s) and diagnostic tools like sFlt1 biomarker that can be used in clinical practice. This goal is difficult to achieve due to multiple factors including medicolegal issues hindering clinical trials recruitment and the nature of the therapies. However, their work paved the road for the development of more novel therapies for the early diagnosis and management of preeclampsia. More research work is needed in genomic, proteomic, clinical and epidemiological domains.

In May, 2019 Phipps et al. [17] published their work regarding the pathogenesis, novel diagnostics, and therapies for pre-eclampsia.They reported that "In the past decade, the discovery and characterization of novel antiangiogenic pathways have been particularly impactful both in increasing understanding of the disease pathophysiology and in directing predictive and therapeutic efforts". Their review included the pathogenic role of antiangiogenic proteins released by the placenta in the development of pre-eclampsia, and novel therapeutic strategies directed at restoring the angiogenic imbalance observed during preeclampsia.

Finally, nephrologists usually do not obtain in-depth into obstetrical histories on their patients. Since emerging reports indicate that preeclampsia is a risk factor for future chronic kidney disease, it is imperative and prudent that they obtain a comprehensive obstetrical history, and screen those with a history of preeclampsia.

\section{References}

1. Osman O, Bakare AO, Elamin S (2011) The prevalence of proteinuria among pregnant women as detected by a semi-quantitative method: a single center experience. Arab $J$ Nephrol Transplant 4: 77-82. [Crossref]

2. Sood A, Stephy M (2017) Audit of Management of Gestational Proteinuria. Obstet Gynecol 129: S128.
3. Gongora MC, Wenger NK (2015) Cardiovascular Complications of Pregnancy. Int J Mol Sci 16: 23905-23928.

4. Behrens I, Basit S, Lykke JA, Ranthe MF, Wohlfahrt J, et al. (2016) Association Between Hypertensive Disorders of Pregnancy and Later Risk of Cardiomyopathy. JAMA 315: 1026-1033. [Crossref]

5. Brown MC, Best KE, Pearce MS, Waugh J, Robson SC, et al. (2013) Cardiovascular disease risk in women with pre-eclampsia: systematic review and meta-analysis. Eur $J$ Epidemiol 28: 1-19. [Crossref]

6. McDonald SD, Malinowski A, Zhou Q, Yusuf S, Devereaux PJ (2008) Cardiovascular sequelae of preeclampsia/eclampsia: a systematic review and meta-analyses. Am Heart $J$ 156: 918-930. [Crossref]

7. Honigberg MC, Zekavat SM, Aragam K, Klarin D, Bhatt DL, et al. (2019) Long-Term Cardiovascular Risk in Women With Hypertension During Pregnancy. J Am Coll Cardiol 74: 2743-2754. [Crossref]

8. Sanghavi M, Rutherford JD (2014) Cardiovascular physiology of pregnancy. Circulation. 130: 1003-1008. [Crossref]

9. Vikse BE, Irgens LM, Leivestad T, Skjaerven R, Iversen BM (2008) Preeclampsia and the risk of end-stage renal disease. $N$ Engl J Med 359: 800-809. [Crossref]

10. Wang IK, Muo CH, Chang YC, Liang CC, Chang CT, et al. (2013) Association between hypertensive disorders during pregnancy and end-stage renal disease: a populationbased study. CMAJ 185: 207-213. [Crossref]

11. Kattah AG, Scantlebury DC, Agarwal S, Mielke MM, Rocca WA, et al. (2017) Preeclampsia and ESRD: The Role of Shared Risk Factors. Am J Kidney Dis 69: 498505. [Crossref]

12. [No authors listed] (2019) ACOG Practice Bulletin No. 202: Gestational Hypertension and Preeclampsia. Obstet Gynecol 133: e1-e25.

13. Kristensen JH, Basit S, Wohlfahrt J, Damholt MB, Boyd HA (2019) Pre-eclampsia and risk of later kidney disease: nationwide cohort study. BMJ 365: 11516.

14. U.S. Preventive Services Task Force (2018) Screening for Preeclampsia: Recommendation Statement. Am Fam Physician 97: Online.

15. Osman O, Maynard S (2019) Proteinuria in pregnancy-Review. Front Womens Health 4: $1-5$.

16. Maynard SE, Min JY, Merchan J, Lim KH, Li J, Mondal S, et al. (2003) Excess placental soluble fms-like tyrosine kinase 1 (sFlt1) may contribute to endothelial dysfunction, hypertension, and proteinuria in preeclampsia. J Clin Invest 111: 649-658. [Crossref]

17. Phipps EA, Thadhani R, Benzing T, Karumanchi SA et al. (2019) Pre-eclampsia: pathogenesis, novel diagnostics and therapies. Nat Rev Nephrol 15: 275-289. [Crossref]

Copyright: (C2019 Osman O. This is an open-access article distributed under the terms of the Creative Commons Attribution License, which permits unrestricted use, distribution, and reproduction in any medium, provided the original author and source are credited. 